\title{
Erwiderung auf die Bemerkungen E. Weils.
}

Von Dr. Julius Citron in Berlin.

In krwiderung auf die Bemerkungen von Herrn W eil beschränke ich mich auf folgende Feststellungen: Weil hat Versnche publiziert, die zeigten, daß Sarkomextrakt zusammen mit Serum von Syphilitikern Komplement biuden kann. Hieraus mußten diejenigen, die mit den Details der Komplementbindungsmethode nnvertrait sind, d. h. das $\mathrm{G}$ ros der Mediziner, schließen, daß die praktische Verwertbarkeit der Serodiagnostik der Syphilis ernstlich erschïttert sei. Dieses ist aber de facto nicht der Fall, denn Weil hat alle Kontrollen, die iberhaupt erst einen Schluß ermöglichen, unterlassen. W eil hätte zeigen miissen 1. daß das Serum seiner Syphilitiker ib berhaupt Lnesantikörper enthielt, was keineswegs selbstverständlich ist; 2 . daß das Serum von Nichtsyphilitischen sich anders als Syphilitikerserum und 3. dal3 die Sarkomextrakte sich anders als Extrakte aus normalen Organen unter seinen Versuchsbedingungen verbielten. Ferner wäre die sehr wichtige Frage zu prufen gewesen, ob sich besondere Be. ziehungen zwischen Sarkom nnd Syphilis nachweisen lassen, indem der Einfln 1 des Serums von Sarkomatosen auf normale, luetische und Sarkomextrakte genau quantitativ zu bestimmen war. Nichts von alledem ist geschehen. Tnter diesen Umständen läBt sich alls $W^{\prime}$ eils Versuchen, die unter Umständen bedeutungsvoll hätten sein können, nur der dürftige Schlul ziehen, daßs gelegentlich ein menschliches Serum mit einem menschlichen Organextrakt Komplement binden kann. Diese Tatsache war nicht neu nod ist der Grund, warum die jetzt von Weil für so "sinnlos“ erklärten Kontrollen notwendig sind. Da Weil seine Versuche ohne Kontrollen anstellte, so hat er, statt unsero Erkenntnis auf dem vorliegenden schwierigen Arbeits- 
gebiet zu fördern, nur in mühsam geklärte $\mathrm{Phänomene} \mathrm{aufs} \mathrm{neue}$ Verwirrung und Unsicherheit hineingebracht.

Die Erklärung dafür, daß Sarkom-, ebenso wie viele syphilitische und normale Organextrakte mit Serum Komplementbindung ergeben können, ist mit Sicherheit zurzeit nicht zu geben. Vielleicht liegt sie darin, daB bei der Autolyse von Organen albumosenartige Stoffe auftreten, die mit den von mir im Schlußteil meines Vortrages beschriebenen Normal-Albumose-Ambozeptoren sich verbinden können. Bei der Einhaltung der von Bruck, Wassermann und mir auf Grund von vielen Hunderten von Versuchen bis in alle Details ausgearbeiteten Methodik haben sich aus diesem Phänomen bei der praktischen Verwertung der Serodiagnostik der Syphilis keinerlei Schwierigkeiten ergeben. Es muB freilich verlangt werden, daß Herren, die uiber den Wert unserer Arbeiten richten wollen, auch die von uns gewählten Versuchsbedingungen einhalten. Hierzu gehört es, daß ein jedes auf diese Antikörper zu untersuchende Serum durch Erhitzen inaktiviert wird. Alte unerhitzte Sera sind, auch wenn sie komplementfrei sind, den erhitzten keineswegs stets gleich zu setzen, denn Sera bestehen bekanntlich nicht nur aus Ambozeptoren und Komplementen, sondern enthalten auch Eiweiße, Fermente und andere Substanzen, die für den Ablauf der Hämolyse nicht gleichgültig sind, wenn wir ihren Einflıß im einzelnen bisher auch noch nicht kennen. Einschlägige Beobachtungen sind in einer Publikation in der Zeitschrift fïr experimentelle Pathologie und Therapie 1907, Bd. 4, S. 304 u. f. mitgeteilt. Es ist daher ein technischer Fehler", wenn die Erhitzung des Serums, wie dies Weil getan hat, unterlassen wird. Mein Urteil über die Arbeit Weils kann ich demnach nur in der Weise zusammenfassen, daß3 "die von Weil in allerletzter Zeit gemachte Mitteilung uber Komplementbindung zwischen Sarkomextrakt und Syphilitikerserum des Fehlens der wichtigsten Kontrollen und eines technischen Fehlers wegen zunächst ohne jede Beweiskraft" ist.

Wenn Herr $W$ eil dann weiter mich für die Arbeiten anderer Autoren, die in den komplementbindenden Substanzen im Serum Syphilitischer Antikörper gegen Spirochätensubstanz sehen wollten, verantwortlich macht, so verstehe ich eine derartige Polemik nicht. Ich vertrete nur die Anschaungen, die ich mit meinem Namen zeichne, nicht die anderer Autoren, die in anderen Laboratorien als in dem der II. Medizinischen Klinik gearbeitet haben. 